\title{
Baseline patient factors impact on the clinical efficacy of benralizumab for severe asthma
}

\author{
Eugene R. Bleecker ${ }^{1}$, Michael E. Wechsler ${ }^{2}$, J. Mark FitzGerald ${ }^{3}$, \\ Andrew Menzies-Gow ${ }^{4}$, Yanping Wu ${ }^{5}$, lan Hirsch ${ }^{5}$, Mitchell Goldman ${ }^{5}$, \\ Paul Newbold ${ }^{6}$ and James G. Zangrilli ${ }^{5}$
}

\begin{abstract}
Affiliations: ${ }^{1}$ Divisions of Pharmacogenomics and Genetics, Genomics and Precision Medicine, University of Arizona College of Medicine, Tucson, AZ, USA. ${ }^{2}$ National Jewish Health, Denver, CO, USA. ${ }^{3}$ Centre for Heart and Lung Health, The Lung Centre, Vancouver General Hospital, UBC Institute for Heart and Lung Health, Vancouver, BC, Canada. ${ }^{4}$ Dept of Asthma and Allergy, Royal Brompton Hospital, London, UK. ${ }^{5}$ AstraZeneca, Gaithersburg, MD, USA. ${ }^{6}$ Medlmmune LLC, Gaithersburg, MD, USA.
\end{abstract}

Correspondence: Eugene R. Bleecker, Division of Genetics, Genomics and Precision Medicine, University of Arizona Dept of Medicine, Division of Pharmacogenomics, University of Arizona Center for Applied Genetics and Genomics Medicine, 1230 North Cherry Avenue, Suite 251, PO Box 210242, Tucson, AZ 85721, USA.

E-mail: erbleeckerdemail.arizona.edu

@ERSpublications

Key baseline factors can aid in identifying patients who may respond to benralizumab http://ow.ly/uPVX30ltHTF

Cite this article as: Bleecker ER, Wechsler ME, FitzGerald JM, et al. Baseline patient factors impact on the clinical efficacy of benralizumab for severe asthma. Eur Respir J 2018; 52: 1800936 [https://doi.org/10.1183/ 13993003.00936-2018].

ABSTRACT Benralizumab is an anti-eosinophilic monoclonal antibody that reduces exacerbations and improves lung function for patients with severe, uncontrolled asthma with eosinophilic inflammation. We evaluated the impact of baseline factors on benralizumab efficacy for patients with severe asthma.

This analysis used pooled data from the SIROCCO (ClinicalTrials.gov identifier NCT01928771) and CALIMA (ClinicalTrials.gov identifier NCT01914757) Phase III studies. Patients aged 12-75 years with severe, uncontrolled asthma receiving high-dosage inhaled corticosteroids plus long-acting $\beta_{2}$-agonists received benralizumab $30 \mathrm{mg}$ subcutaneously every 8 weeks (Q8W, first three doses every 4 weeks (Q4W)), Q4W or placebo. Baseline factors that influenced benralizumab efficacy were evaluated, including oral corticosteroid (OCS) use, nasal polyposis, pre-bronchodilator forced vital capacity (FVC), prior year exacerbations and age at diagnosis. Efficacy outcomes included annual exacerbation rate and change in pre-bronchodilator forced expiratory volume in $1 \mathrm{~s}$ at treatment end relative to placebo.

Benralizumab Q8W treatment effect was enhanced with each baseline factor for all patients and those with $\geqslant 300$ eosinophils $\mu \mathrm{L}^{-1}$ relative to the overall population. OCS use, nasal polyposis and $\mathrm{FVC}<65 \%$ of predicted were associated with greater benralizumab Q8W responsiveness for reduced exacerbation rate for patients with $<300$ eosinophils $\mu \mathrm{L}^{-1}$.

Baseline clinical factors and blood eosinophil counts can help identify patients potentially responsive to benralizumab.

This article has supplementary material available from erj.ersjournals.com

Received: May 182018 | Accepted after revision: Aug 132018

Copyright $\odot$ ERS 2018. This article is open access and distributed under the terms of the Creative Commons Attribution Non-Commercial Licence 4.0. 


\section{Introduction}

Asthma is a heterogeneous disease that affects more than 315 million people worldwide, with various factors influencing its severity and control [1-3]. Approximately $10 \%$ of patients have severe, uncontrolled asthma, which is associated with substantial disease burden, diminished health-related quality of life and increased healthcare resource utilisation [4-6]. Patients with severe asthma require high-dosage inhaled corticosteroid (ICS) plus long-acting $\beta_{2}$-agonist (LABA) combination therapy and often additional controller medications, including oral corticosteroids (OCSs) for disease control [7]. However, even with these therapies, many patients with severe asthma continue to have uncontrolled symptoms and poor asthma control, emphasising the need for new treatment options [5].

Eosinophilic inflammation of the airways is an important feature of asthma that affects $~ 50 \%$ of patients, and is associated with increased disease severity, exacerbation frequency and symptom burden, together with decreased lung function [8-10]. Therapeutic approaches to reduce eosinophilic inflammation that target the interleukin (IL)-5 receptor $\alpha$ and anti-IL-5 monoclonal antibodies have demonstrated clinical efficacy for patients with severe asthma and evidence of eosinophilic inflammation, based on elevated blood eosinophil counts [11-15]. Elevated blood eosinophil counts are practical to measure and demonstrate significant associations with eosinophilic airway inflammation, but the measure is indirect and lacks specificity, especially at low eosinophil counts [16-18]. Additional clinical features beyond blood eosinophilia need to be identified to aid in the selection of patients who might benefit from these novel treatments.

Benralizumab is a humanised, afucosylated, monoclonal antibody that targets the IL-5 receptor $\alpha$ [19]. In contrast to anti-IL-5 monoclonal antibodies, benralizumab exerts its effect by inducing the direct, rapid and nearly complete depletion of blood eosinophils through enhanced antibody-dependent cell-mediated cytotoxicity, an apoptotic process of eosinophil elimination involving natural killer cells [19, 20]. Airway eosinophils (tissue and sputum) are also extensively depleted [21, 22]. Two Phase III trials, SIROCCO (ClinicalTrials.gov identifier NCT01928771) and CALIMA (ClinicalTrials.gov identifier NCT01914757), demonstrated that benralizumab in combination with high-dosage ICS/LABA, with or without additional controllers, significantly reduced asthma exacerbations and improved lung function and disease control for patients with severe, uncontrolled asthma and blood eosinophil counts $\geqslant 300$ cells. $\mu \mathrm{L}^{-1}$ versus placebo [11, 12]. A third Phase III trial, ZONDA (ClinicalTrials.gov identifier NCT02075255), demonstrated that for OCS-dependent patients, benralizumab significantly reduced the use of maintenance prednisone while maintaining asthma control [23]. Benralizumab $30 \mathrm{mg}$ subcutaneous formulation administered every 8 weeks (Q8W, first three doses every 4 weeks (Q4W)) has subsequently been approved in several markets as add-on maintenance treatment for patients with severe, uncontrolled eosinophilic asthma $[24,25]$.

Statistical analyses of the Phase III studies identified several baseline clinical factors associated with enhanced efficacy to benralizumab, regardless of blood eosinophil counts, including OCS use, history of nasal polyposis, lung function based on pre-bronchodilator forced vital capacity (FVC), exacerbation frequency and age at asthma diagnosis [26]. The current study evaluates these factors in the pooled SIROCCO and CALIMA patient population, including subsets of those with blood eosinophil counts $<300$ and $\geqslant 300$ cells $\mu \mathrm{L}^{-1}$.

\section{Methods}

\section{Study design and participants}

SIROCCO and CALIMA were randomised, double-blind, parallel-group, placebo-controlled, global Phase III studies $[11,12]$. The study design comprised an enrolment visit (week -4), a 4-week screening/ run-in phase, randomisation (week 0), a treatment period from weeks 0 to 48 (SIROCCO) or 56 (CALIMA) and a final follow-up visit 8 (SIROCCO) or 4 (CALIMA) weeks following the end-of-treatment (EOT) period.

Enrolment criteria for the studies have been previously reported [11, 12]. The studies included male and female patients aged $12-75$ years with weight $\geqslant 40 \mathrm{~kg}$ and physician-diagnosed asthma that required treatment with medium/high-dosage ICS/LABA for $\geqslant 12$ months before enrolment. Studies were conducted in accordance with the Declaration of Helsinki, International Conference on Harmonisation of Technical Requirements for Registration of Pharmaceuticals for Human Use/Good Clinical Practice guidelines and the ethics committee at each participating site.

For both studies, patients were randomised 1:1:1 to receive either s.c. benralizumab $30 \mathrm{mg}$ Q4W, benralizumab $30 \mathrm{mg}$ Q4W for the first three doses followed by Q8W for the remainder of the treatment period or placebo $(\mathrm{Q} 4 \mathrm{~W})$. For SIROCCO and CALIMA, patients with baseline blood eosinophil counts $\geqslant 300$ and $<300$ cells $\mu \mathrm{L}^{-1}$ were stratified at a ratio of $2: 1$, respectively. 


\section{Outcomes}

The primary efficacy end-point for SIROCCO and CALIMA was the annual asthma exacerbation rate (AER). For both studies, the primary analysis set included patients receiving high-dosage ICS/LABA with baseline blood eosinophil counts $\geqslant 300$ cells $\mu \mathrm{L}^{-1}$. Secondary end-points for the primary analysis population evaluated in this current study were change from baseline at EOT for pre-bronchodilator forced expiratory volume in $1 \mathrm{~s}(\mathrm{FEV} 1)$, measured by spirometry, total asthma symptom score (a composite of daytime and night-time symptoms scored 0-6 points overall) and Asthma Control Questionnaire 6 (ACQ-6) score. ACQ-6 is a six-item questionnaire to assess daytime and night-time symptoms and rescue $\beta$-agonist use on a 0-6-point scale (small numbers represent better control) [27]. Details on efficacy measurement methods have been published previously [11, 12].

In the current study, analyses were performed for the pooled population of patients from the SIROCCO and CALIMA studies receiving high-dosage ICS/LABA. Baseline patient factors were selected for evaluation in this study based on the results of four separate statistical analyses and by considering features that are commonly associated with an eosinophilic asthma phenotype [28, 29]. Two of the approaches explored the relative importance of different response factors for the same population [26], a third approach compared patients from a pooled analysis of SIROCCO and CALIMA on defined efficacy improvements with benralizumab, and the fourth approach evaluated patients from ZONDA based on reduction in OCS dosage with benralizumab (more details provided in supplementary appendix E1, and supplementary tables E1 and E2) [23]. These baseline factors include OCS use (yes/no); presence of nasal polyps (yes/no); low lung function based on pre-bronchodilator FVC categories of $<65 \%$ and $\geqslant 65 \%$ of predicted (categories based on a quartile analysis of baseline FVC $\%$ pred of the pooled SIROCCO and CALIMA data; see supplementary appendix E1 and supplementary figure E1); exacerbations in the 12 months before enrolment categories of two and three or more; and age at diagnosis categories of $<18$ and $\geqslant 18$ years (see supplementary appendix E1 for rationale). Subgroups analysed within these categories were baseline blood eosinophil counts $\left(\geqslant 300\right.$ and $<300$ cells $\left.\mu \mathrm{L}^{-1}\right)$. For this study, end-points evaluated were AER, and change from baseline to EOT in pre-bronchodilator FEV1, total asthma symptom score and ACQ-6 score.

\section{Statistical analyses of end-points}

We performed analyses based on the full analysis set according to the intention-to-treat principle for the pooled data from the SIROCCO and CALIMA studies. This set included all randomised patients who received high-dosage ICS/LABA and any study treatment, regardless of their protocol adherence, and continued participation in the study. The similar design of the two studies allowed for the results to be pooled, which enabled us to obtain more accurate estimates of the relationships between efficacy endpoints and OCS use at baseline, presence of nasal polyps and FVC \% pred. Analyses were performed with SAS versions 9.2, 9.3 and 9.4 (SAS Institute, Cary, NC, USA).

We analysed exacerbation rates using a negative binomial model, with adjustments for treatment, study region (all groups), prior exacerbations and OCS use at time of randomisation where applicable for all patients and for those with blood eosinophil counts $\geqslant 300$ cells $\mu \mathrm{L}^{-1}$. The log of each patient's corresponding follow-up time was used as an offset variable in the model to adjust for different exposure times during which the events occurred. We determined the estimated AER treatment effect (i.e. the rate ratio of benralizumab versus placebo), corresponding 95\% confidence interval and two-sided p-value for the rate ratio. Pre-bronchodilator FEV1, total asthma symptom score and ACQ-6 were analysed using a mixed-effects model for repeated measures analysis, with adjustments for treatment, study, baseline value, visit, visit $\times$ treatment and region (all groups), and, where applicable, OCS use at time of randomisation for all patients and for those with blood eosinophil counts $\geqslant 300$ cells $\mu \mathrm{L}^{-1}$. The EOT visit for each study was included in the model and used as the primary time-point.

To account for the 2:1 stratification for baseline blood eosinophil counts $\left(\geqslant 300\right.$ and $\left.<300 \mathrm{cells} \cdot \mu \mathrm{L}^{-1}\right)$ in analyses for all patients, we reweighted patients with baseline blood eosinophil counts $<300$ cells $\mu \mathrm{L}^{-1}$ by using the ratio of the number of patients with baseline blood eosinophil counts $\geqslant 300 \mathrm{cells} \cdot \mu \mathrm{L}^{-1}$ to the number of those who had counts $<300$ cells $\mu \mathrm{L}^{-1}$. Given the smaller number of patients with blood eosinophil counts $<300$ cells $\mu \mathrm{L}^{-1}$ and the respective baseline factors evaluated, only adjustments for study code and treatment for the negative binomial model and for study code, treatment, baseline value, visit and visit $\times$ treatment for the mixed-effects model for repeated measures analysis were used within this subgroup of patients.

We calculated least squares means, treatment differences in least squares means, 95\% confidence intervals and p-values. As these analyses were not part of the formal testing strategy, all p-values were nominal. 


\section{Results}

\section{Demographics and baseline clinical characteristics}

The three treatment groups shared similar demographics and baseline clinical characteristics, particularly for the baseline factors evaluated in this study (table 1).

\section{Clinical factors identified for enhanced efficacy}

Based on the results of the four separate statistical analyses of the same population, as described in the Methods section and supplementary appendix E1, the following clinical factors were selected for further evaluation: OCS use, nasal polyposis, pre-bronchodilator FVC $<65 \%$ of predicted, three or more exacerbations in the previous year and age at diagnosis $\geqslant 18$ years. Only the indicated Q8W dosage of benralizumab is discussed in this article. The Q4W results are provided in supplementary tables E3-E14 for completeness, as they were part of the SIROCCO and CALIMA studies.

\section{Baseline factor influence on benralizumab-mediated exacerbation rate reduction}

A greater reduction in AER was observed for patients in the overall population and those with blood eosinophil counts $\geqslant 300$ cells $\mu \mathrm{L}^{-1}$ receiving benralizumab Q8W and with any baseline factor evaluated compared with the efficacy in the full analysis set (FAS) (figures 1 and 2, and supplementary tables E3 and E4). For the overall population, OCS use (rate ratio 0.42, 95\% CI 0.29-0.60; nominal $\mathrm{p}<0.001$ ) and nasal polyposis (rate ratio 0.50, 95\% CI 0.35-0.72; nominal $\mathrm{p}<0.001$ ) had the greatest influence on improvement of AER with benralizumab Q8W versus placebo compared with the FAS, with a rate ratio for the FAS of 0.64 (95\% CI $0.55-0.75$; nominal $\mathrm{p}<0.001)$. For patients with blood eosinophil counts $<300$ cells $\mu \mathrm{L}^{-1}$, OCS use (rate ratio $0.44,95 \%$ CI $0.26-0.74$; nominal $\mathrm{p}=0.002$ ), nasal polyposis (rate ratio 0.49 , 95\% CI $0.21-1.19$; nominal $\mathrm{p}=0.115$ ) and pre-bronchodilator $\mathrm{FVC}<65 \%$ of predicted (rate ratio 0.57 ,

\begin{tabular}{|c|c|c|c|}
\hline & Placebo & $\begin{array}{l}\text { Benralizumab } \\
30 \text { mg Q4W }\end{array}$ & $\begin{array}{l}\text { Benralizumab } \\
30 \mathrm{mg} \mathrm{Q8W}\end{array}$ \\
\hline Patients & 777 & 756 & 762 \\
\hline Age years & $49.2 \pm 14.6$ & $50.4 \pm 13.2$ & $48.8 \pm 14.0$ \\
\hline \multicolumn{4}{|l|}{ Sex } \\
\hline Male & $287(37)$ & $251(33)$ & 285 (37) \\
\hline Female & $490(63)$ & $505(67)$ & 477 (63) \\
\hline \multicolumn{4}{|l|}{ Ethnicity } \\
\hline White & $623(80)$ & $593(78)$ & $597(78)$ \\
\hline Black or African-American & $28(4)$ & $23(3)$ & $28(4)$ \\
\hline Asian & $87(11)$ & $95(13)$ & $90(12)$ \\
\hline Other ${ }^{\text {I }}$ & 39 (5) & $45(6)$ & $47(6)$ \\
\hline $\mathrm{BMI}^{+} \mathrm{kg} \cdot \mathrm{m}^{-2}$ & $29.1 \pm 6.8$ & $29.1 \pm 7.0$ & $28.6 \pm 6.3$ \\
\hline Eosinophil count ${ }^{+}$cells $\mu^{-1}$ & $375(0-4494)$ & $380(0-3440)$ & $380(0-3100)$ \\
\hline Pre-bronchodilator $\mathrm{FEV}_{1}{ }^{+} \mathrm{L}$ & $1.71 \pm 0.61$ & $1.70 \pm 0.57$ & $1.70 \pm 0.60$ \\
\hline Pre-bronchodilator $\mathrm{FEV}_{1}{ }^{+} \%$ pred & $57.0 \pm 14.9$ & $57.9 \pm 14.3$ & $56.5 \pm 14.6$ \\
\hline Pre-bronchodilator $\mathrm{FEV}_{1} / \mathrm{FVC}^{+} \%$ & $61 \pm 13$ & $61 \pm 12$ & $60 \pm 13$ \\
\hline Reversibility ${ }^{+} \%$ & $20(-26-814)$ & $19(-24-809)$ & $21(-13-171)$ \\
\hline Pre-bronchodilator $\mathrm{FVC}^{+} \%$ pred & $75.6(19.2-122.4)$ & $76.3(21.9-125.3)$ & $76.1(33.4-143.1)$ \\
\hline Time since asthma diagnosis years & $15.5(1.1-72.4)$ & $15.3(1.1-70.4)$ & $15.2(1.1-66.9)$ \\
\hline Age at asthma diagnosis years & $31.6(0.0-72.4)$ & $34.6(0.0-71.1)$ & $32.0(0.0-72.0)$ \\
\hline Exacerbations in the past 12 months $n$ & $2.0(2.0-20.0)$ & $2.0(1.0-22.0)$ & $2.0(1.0-15.0)$ \\
\hline TASS $^{+}$ & $2.7 \pm 1.1$ & $2.7 \pm 1.0$ & $2.7 \pm 1.1$ \\
\hline ACQ-6 score & $2.8 \pm 0.9$ & $2.8 \pm 0.9$ & $2.8 \pm 0.9$ \\
\hline$A Q L Q(S)+12$ score $^{+}$ & $3.9 \pm 1.0$ & $4.0 \pm 1.0$ & $3.9 \pm 1.0$ \\
\hline Nasal polyps & $146(19)$ & $136(18)$ & $135(18)$ \\
\hline Atopic & $463(60)$ & 444 (59) & $468(61)$ \\
\hline OCS use & $109(14)$ & $90(12)$ & $110(14)$ \\
\hline
\end{tabular}

Data are presented as $\mathrm{n}$, mean \pm SD, $\mathrm{n}(\%)$ or median (range). Q4W: every 4 weeks; Q8W: every 8 weeks (first three doses Q4W); BMI: body mass index; FEV1: forced expiratory volume in $1 \mathrm{~s}$; FVC: forced vital capacity; TASS: total asthma symptom score; ACQ-6: Asthma Control Questionnaire 6; AQLQ(S)+12: Asthma Quality of Life Questionnaire (standardised) for $\geqslant 12$ years; OCS: oral corticosteroid. \# : pooled population of $n=2295$ patients from the SIROCCO and CALIMA studies who received high-dosage inhaled corticosteroid plus long-acting $\beta_{2}$-agonist; ": native Hawaiian or other Pacific Islander, American Indian, Alaska Native and Other; ${ }^{+}$: data not available for all randomised patients. 


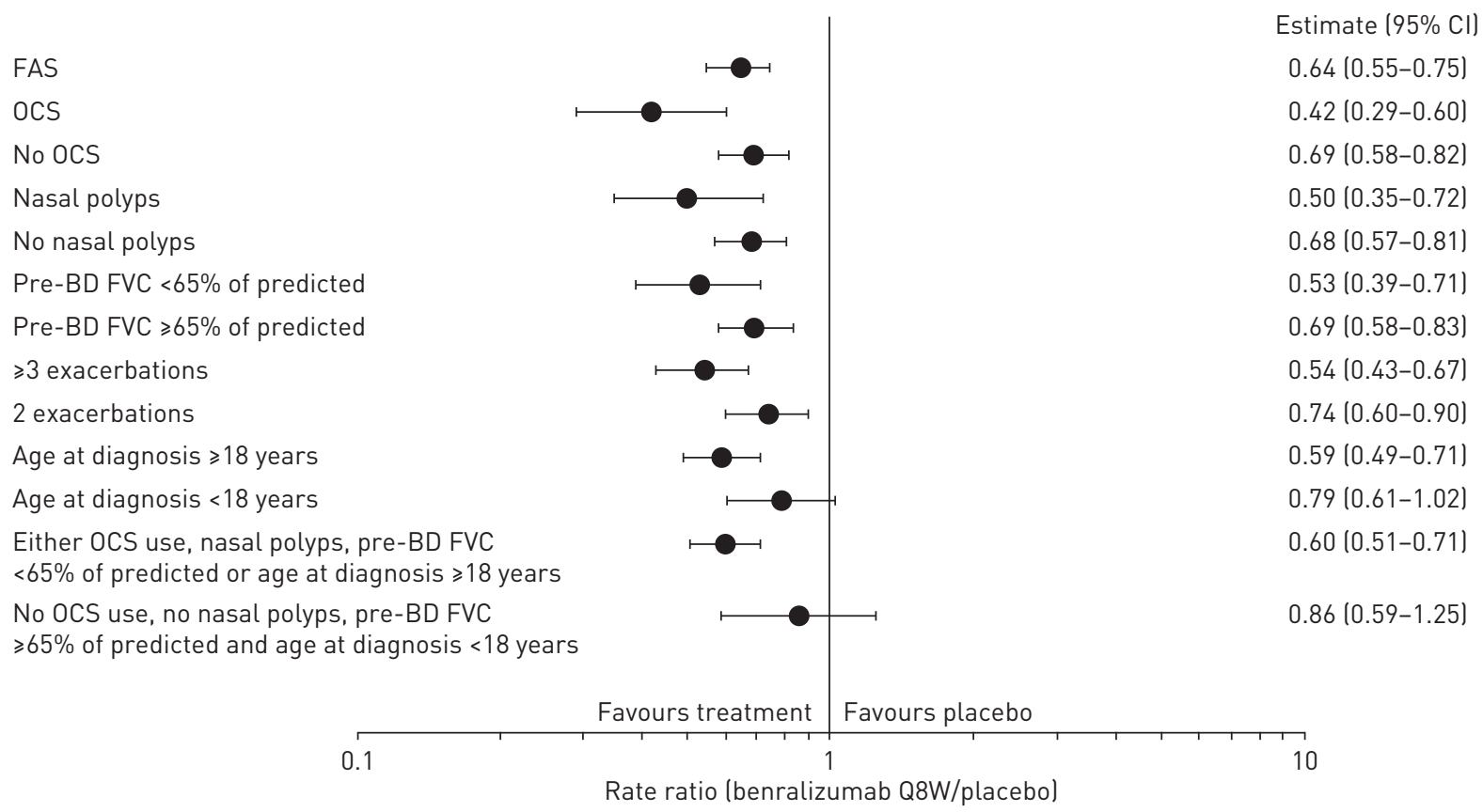

FIGURE 1 Forest plot of baseline factor effect on annual exacerbation rate ratio with benralizumab every 8 weeks (Q8W, first three doses every 4 weeks) and high-dosage inhaled corticosteroid (ICS) plus long-acting $\beta_{2}$-agonist (LABA) for the overall population (full analysis set (FAS), pooled). OCS: oral corticosteroid; BD: bronchodilator; FVC: forced vital capacity. Data are from the pooled intention-to-treat population from the high-dosage ICS/LABA treatment cohorts of the SIROCCO and CALIMA studies. Estimates were reweighted to account for the 2:1 stratification for baseline blood eosinophil counts $\left(\geqslant 300\right.$ and $<300$ cells. $\left.\mu \mathrm{L}^{-1}\right)$. Estimates were calculated by using a negative binomial model with adjustment for study code, region, OCS use at time of randomisation where applicable, prior year exacerbations and treatment. The log of each patient's corresponding follow-up time was used as an offset variable in the model to adjust for different exposure times during which the events occurred.

95\% CI 0.36-0.92; nominal $\mathrm{p}=0.021$ ) had a notable influence on improving benralizumab Q8W AER efficacy compared with the efficacy in the FAS (rate ratio 0.73 , 95\% CI $0.57-0.94$; nominal $\mathrm{p}=0.013$ ), despite the smaller number of patients (figure 2 and supplementary table E5).

\section{Baseline factor influence on benralizumab-mediated lung function improvements}

Patients with any baseline clinical factor evaluated had greater lung function improvements with benralizumab Q8W versus placebo compared with the efficacy in the overall FAS and in the population of patients with blood eosinophil counts $\geqslant 300$ cells. $\mu \mathrm{L}^{-1}$ (figures 3 and 4 , and supplemental tables E6 and E7). For the overall population, nasal polyposis (least squares mean difference $0.29 \mathrm{~L}, 95 \%$ CI $0.17-0.41 \mathrm{~L}$; nominal $\mathrm{p}<0.001$ ) and pre-bronchodilator $\mathrm{FVC}<65 \%$ of predicted (least squares mean difference $0.21 \mathrm{~L}$, 95\% CI $0.10-0.31 \mathrm{~L}$; nominal $\mathrm{p}<0.001$ ) had the greatest influence on increasing FEV1 with benralizumab Q8W versus placebo compared with the FAS (least squares mean difference $0.10 \mathrm{~L}, 95 \%$ CI $0.05-0.14 \mathrm{~L}$; nominal $\mathrm{p}<0.001$ ). Similarly, for patients with blood eosinophil counts $<300 \mathrm{cells} \cdot \mu \mathrm{L}^{-1}$, nasal polyposis (least squares mean difference $0.24 \mathrm{~L}, 95 \%$ CI $0.0-0.48 \mathrm{~L}$; nominal $\mathrm{p}=0.045$ ) and pre-bronchodilator FVC $<65 \%$ of predicted (least squares mean difference $0.11 \mathrm{~L}, 95 \% \mathrm{CI}-0.04-0.26 \mathrm{~L}$; nominal $\mathrm{p}=0.146$ ) had the greatest influence of all evaluated baseline factors on improving benralizumab Q8W FEV1 efficacy compared with the efficacy in the FAS (least squares mean difference $0.05 \mathrm{~L}, 95 \% \mathrm{CI}-0.03-0.12 \mathrm{~L}$; nominal $\mathrm{p}=0.238$ ) (figure 4 and supplementary table E8).

\section{Baseline factor influence on benralizumab-mediated improvements in asthma symptoms and control}

Greater improvement in asthma symptoms with benralizumab Q8W versus placebo was observed for patients, both overall and those with blood eosinophil counts $\geqslant 300$ cells $\mu \mathrm{L}^{-1}$, having any baseline factor evaluated (for OCS use, overall only) compared with the efficacy in the FAS (figure 5, and supplementary tables E9 and E10). The greatest baseline factor-associated reduction in total asthma symptom score for the overall patient population treated with benralizumab Q8W versus placebo compared with the efficacy in the FAS (least squares mean difference $-0.18,95 \%$ CI $-0.30--0.07$; nominal $p=0.002$ ) occurred for those with nasal polyposis (least squares mean difference $-0.35,95 \% \mathrm{CI}-0.59--0.10$; nominal $\mathrm{p}=0.005$ ) and OCS use (least squares mean difference $-0.31,95 \%$ CI $-0.60--0.02$; nominal $p=0.038$ ). For patients with blood eosinophil counts $<300$ cells $\mu \mathrm{L}^{-1}$, nasal polyposis (least squares mean difference $-0.46,95 \%$ 

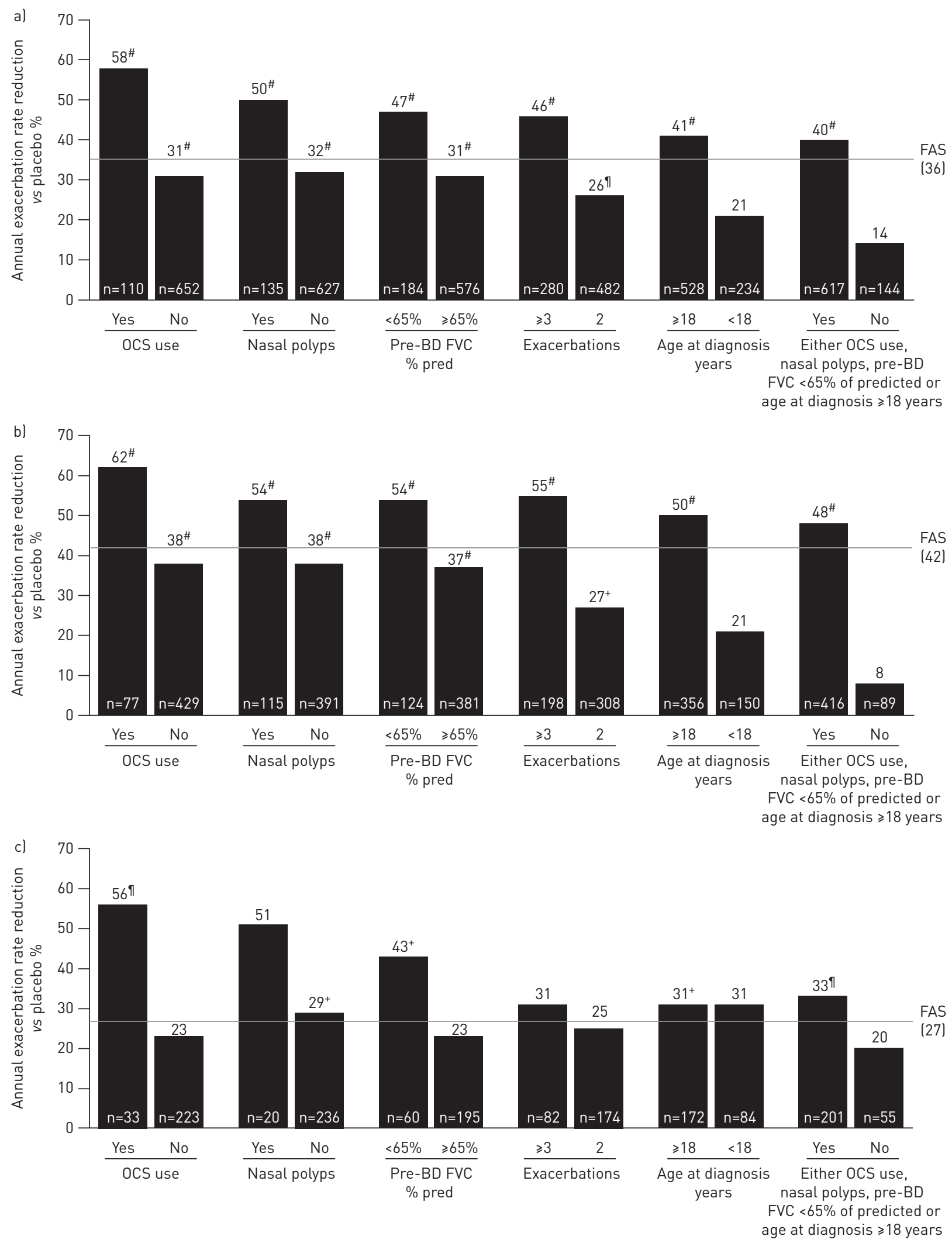

FIGURE 2 Influence of baseline factors on annual exacerbation rate reduction with benralizumab every 8 weeks (Q8W, first three doses every 4 weeks) and high-dosage inhaled corticosteroid plus long-acting $\beta_{2}$-agonist (full analysis set (FAS), pooled): a) overall, b) $\geqslant 300$ eosinophils $\mu L^{-1}$ and c) $<300$ eosinophils $\mu \mathrm{L}^{-1}$. OCS: oral corticosteroid; BD: bronchodilator; FVC: forced vital capacity. \#: nominal $p$-value $<0.001$; ${ }^{\Uparrow}$ : nominal $\mathrm{p}$-value $\geqslant 0.001-\leqslant 0.01 ;{ }^{+}$: nominal $\mathrm{p}$-value $>0.01-\leqslant 0.05$. $\mathrm{n}$-values for number of benralizumab Q8W patients included in the model presented (placebo cohort $n$-values in supplementary tables E1-E3). 


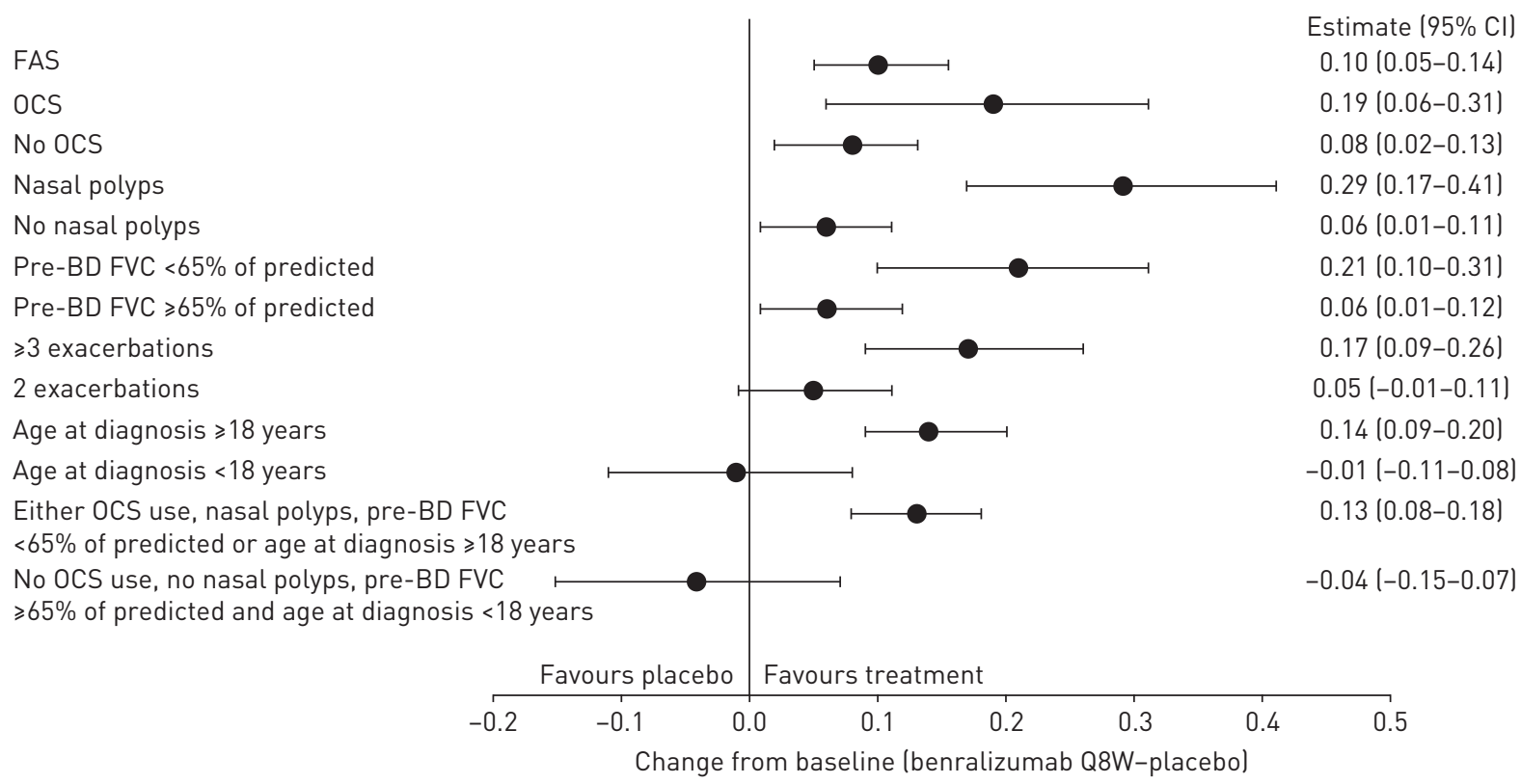

FIGURE 3 Forest plot of baseline factor effect on pre-bronchodilator (BD) forced expiratory volume in $1 \mathrm{~s}(\mathrm{FEV} 1$ ) (L) change (end-of-treatment (EOT)-baseline) improvements with benralizumab every 8 weeks (Q8W, first three doses every 4 weeks) and high-dosage inhaled corticosteroid (ICS) plus long-acting $\beta_{2}$-agonist (LABA) for the overall population (full analysis set (FAS), pooled). OCS: oral corticosteroid; BD: bronchodilator; FVC: forced vital capacity. Data are from the pooled intention-to-treat population from the high-dosage ICS/LABA treatment cohorts of the SIROCCO and CALIMA studies. Estimates were reweighted to account for the 2:1 stratification for baseline blood eosinophil counts $(\geqslant 300$ and $<300$ cells $\mu \mathrm{L}^{-1}$ ). Pre-BD FEV1 change is from baseline (i.e. last value before randomisation) to EOT (SIROCCO: week 48; CALIMA: week 56). Estimates were calculated by using a mixed-effects model for repeated measures analysis with adjustment for study code, treatment, baseline value, region, OCS use at time of randomisation where applicable, visit and visitxtreatment.

CI $-1.02-0.10$; nominal $\mathrm{p}=0.107$ ) and OCS use (least squares mean difference $-0.31,95 \%$ CI $-0.80-0.18$; nominal $\mathrm{p}=0.210$ ) had the greatest influence of all evaluated baseline factors on improving benralizumab Q8W total asthma symptom score efficacy compared with the efficacy in the FAS (least squares mean difference $-0.14,95 \% \mathrm{CI}-0.34-0.06$; nominal $\mathrm{p}=0.178$ ) (figure 5 and supplementary table E11).

For ACQ-6 score, OCS use was consistently the strongest baseline factor associated with enhanced benralizumab Q8W-mediated efficacy improvements relative to placebo, regardless of blood eosinophil count (figure 6 and supplementary tables E12-E14). For patients with blood eosinophil counts $<300$ cells $\mu \mathrm{L}^{-1}$ using OCS, there was a -0.47 least squares mean difference versus placebo in ACQ-6 score (95\% CI -0.99-0.04; nominal $\mathrm{p}=0.072$ ) compared with -0.18 least squares mean difference $(95 \%$ CI $-0.37-0.01$; nominal $\mathrm{p}=0.066$ ) for the FAS.

\section{Discussion}

Benralizumab is an anti-eosinophilic monoclonal antibody that depletes eosinophils through antibody-dependent cellular cytotoxicity, and significantly reduces asthma exacerbations and improves disease control for patients with severe, uncontrolled asthma and elevated blood eosinophils [11, 12, 26]. For patients in the pooled SIROCCO and CALIMA studies receiving high-dosage ICS/LABA and with blood eosinophil counts $\geqslant 300$ cells $\mu \mathrm{L}^{-1}$, benralizumab Q8W decreased exacerbations by $42 \%(\mathrm{p}<0.001)$ and increased pre-bronchodilator FEV1 by $0.14 \mathrm{~L}(\mathrm{p}<0.001)$ relative to placebo. In a previous report of the pooled studies, clinical efficacy of benralizumab was associated with elevated baseline blood eosinophil counts and history of exacerbations [26]. Although other predictive clinical features associated with the severe eosinophilic asthma phenotype were reported, these earlier analyses of clinical features were not quantitative and were not specifically evaluated for patients with nonelevated blood eosinophil counts (i.e. $<300$ cells $\left.\mu \mathrm{L}^{-1}\right)$, a common clinical presentation [26].

In the current study, we evaluated several baseline clinical factors reported to be associated with the severe eosinophilic asthma phenotype in relation to benralizumab efficacy $[28,29]$. The selection of these factors was based on several analyses, including the aforementioned unbiased analysis, that evaluated the relative influence of baseline factors on predicting enhanced benralizumab efficacy for reducing exacerbations and improving lung function (supplementary appendix E1) [26]. These factors included maintenance OCS use, history of nasal polyposis, low lung function based on a pre-bronchodilator FVC $<65 \%$ of predicted, adult 


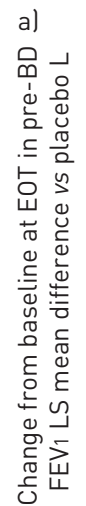

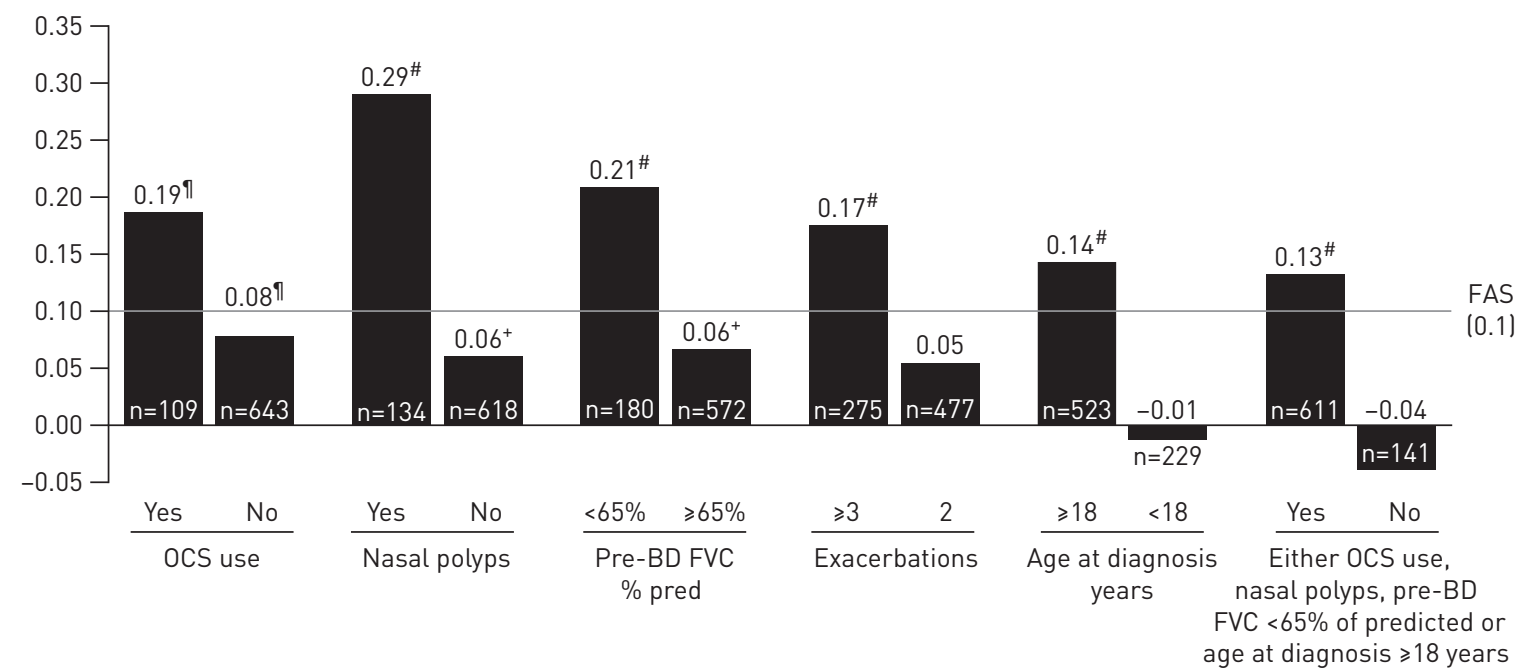

b)

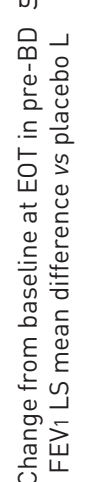

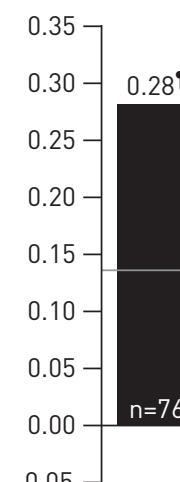

0.27

$\frac{\text { Yes No }}{\text { OCS use }}$

$\frac{\text { Yes } \quad \text { No }}{\text { Nasal polyps }}$

$\frac{<65 \% \quad \geqslant 65 \%}{\begin{array}{c}\text { Pre-BD FVC } \\ \% \text { pred }\end{array}}$

$\geqslant 3 \quad 2$
Exacerbations

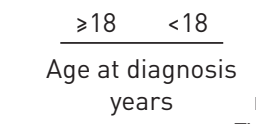

ge at diagnosis $\geqslant 18$ years

FAS 

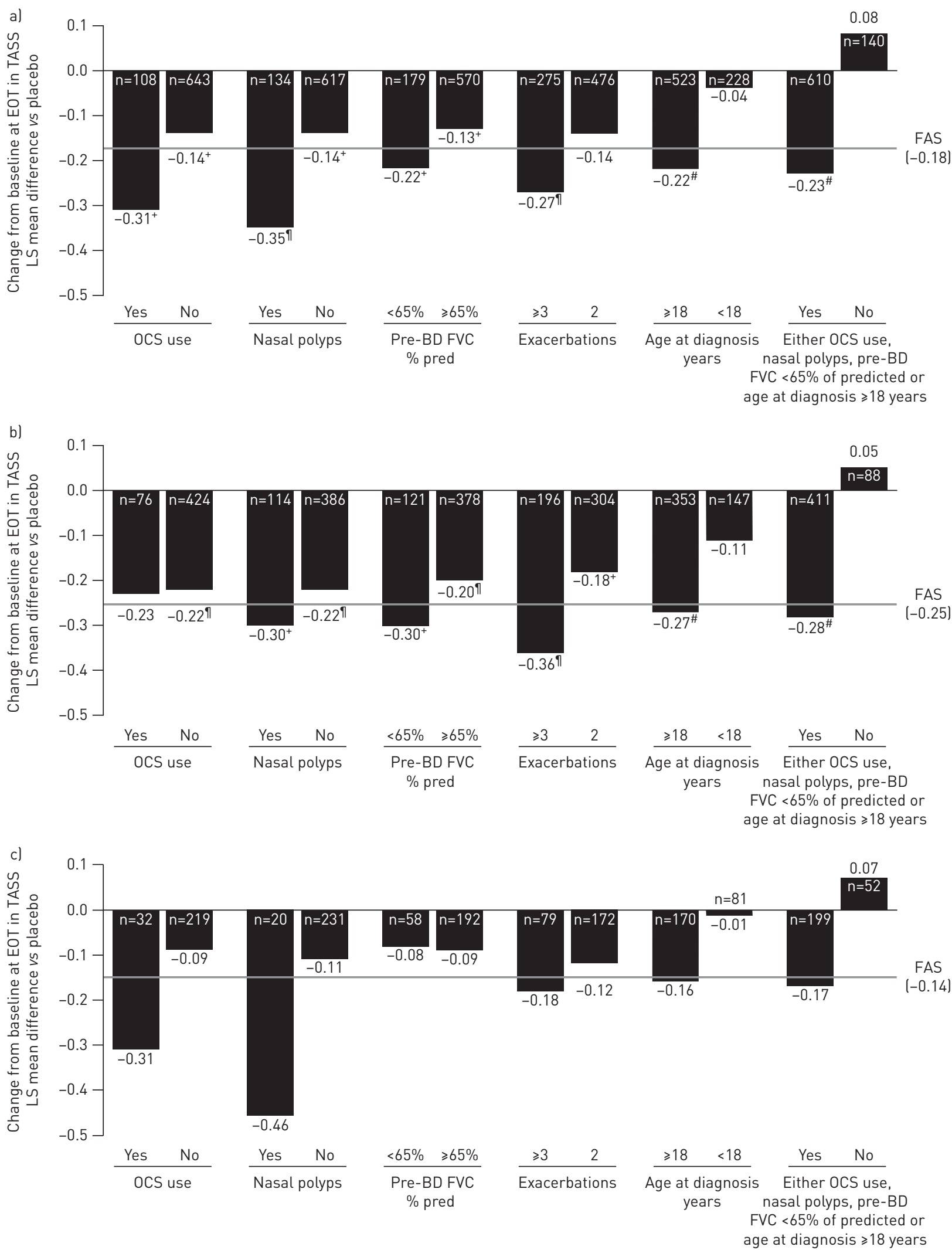

FIGURE 5 Influence of baseline factors on total asthma symptom score (TASS) change (end-of-treatment (EOT)-baseline) improvements with benralizumab every 8 weeks (Q8W, first three doses every 4 weeks) and high-dosage inhaled corticosteroid plus long-acting $\beta_{2}$-agonist (full analysis set (FAS), pooled): a) overall, b) $\geqslant 300$ eosinophils $\mu \mathrm{L}^{-1}$ and $\left.c\right)<300$ eosinophils. $\mu \mathrm{L}^{-1}$. LS: least squares; OCS: oral corticosteroid; BD: bronchodilator; FVC: forced vital capacity. ${ }^{\#}$ : nominal $p$-value $<0.001 ;{ }^{\uparrow}$ : nominal $p$-value $\geqslant 0.001-\leqslant 0.01 ;{ }^{+}$: nominal $p$-value $>0.01-\leqslant 0.05$. $n$-values for number of benralizumab Q8W patients included in the model presented (placebo cohort $\mathrm{n}$-values in supplementary tables E7-E9). 

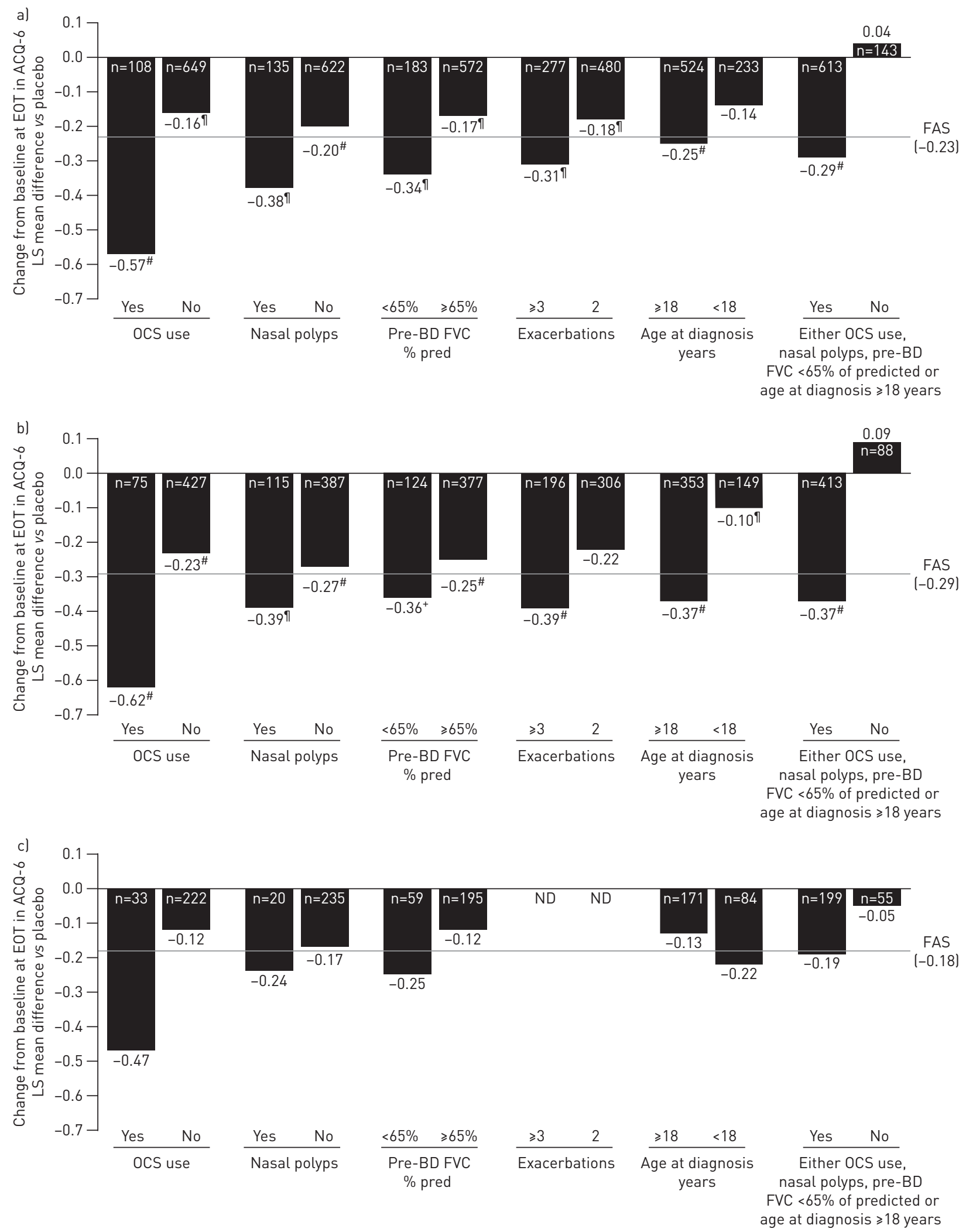

FIGURE 6 Influence of baseline factors on Asthma Control Questionnaire 6 (ACQ-6) change (end-of-treatment (EOT)-baseline) improvements with benralizumab every 8 weeks (Q8W, first three doses every 4 weeks) and high-dosage inhaled corticosteroid plus long-acting $\beta_{2}$-agonist (full analysis set (FAS), pooled): a) overall, b) $\geqslant 300$ eosinophils $\mu \mathrm{L}^{-1}$ and c) $<300$ eosinophils $\mu \mathrm{L}^{-1}$. LS: least squares; OCS: oral corticosteroid; BD: bronchodilator; FVC: forced vital capacity; ND: not determined because of small sample size. ${ }^{\#}$ : nominal $p$-value $<0.001$; ๆ: nominal $p$-value $\geqslant 0.001-\leqslant 0.01 ;{ }^{+}$: nominal $p$-value $>0.01-\leqslant 0.05$. $n$-values for number of benralizumab Q8W patients included in the model presented (placebo cohort $n$-values in supplementary tables E10-E12). 
onset of disease (age $\geqslant 18$ years) and history of frequent exacerbations (three or more in the previous 12 months).

In this study, OCS use, nasal polyposis, pre-bronchodilator FVC $<65 \%$ of predicted, three or more exacerbations in the previous year and age at diagnosis $\geqslant 18$ years were all associated with enhanced responsiveness to benralizumab Q8W treatment for reducing exacerbations and increasing lung function for the overall patient population and for those with baseline blood eosinophil counts $\geqslant 300$ cells $\mu \mathrm{L}^{-1}$. Conversely, patients with none of these features were least responsive to benralizumab Q8W. Although it would be interesting to speculate that patients with a combination of these features would have greater responsiveness to benralizumab than those with individual features, because of low patient numbers, we cannot adequately address this possibility. A total of 12 patients with combined OCS use, nasal polyposis, pre-bronchodilator FVC $<65 \%$ of predicted and age at diagnosis $\geqslant 18$ years treated with benralizumab Q8W demonstrated a 69\% (95\% CI 25-87\%) improvement in exacerbation rates compared with placebo. Patients with a combination of pre-bronchodilator FVC $<65 \%$ of predicted, age at diagnosis $\geqslant 18$ years, OCS use and no nasal polyposis had a 76\% (95\% CI $45-89 \%$; $=23$ ) improvement, and those with a combination of pre-bronchodilator FVC $<65 \%$ of predicted, age at diagnosis $\geqslant 18$ years, nasal polyposis and no OCS use had a 78\% (95\% CI 43-91\%; n=26) improvement in exacerbation rate with benralizumab Q8W compared with placebo.

Adequate phenotyping of patients with low blood eosinophil counts is particularly important before initiation of a highly targeted asthma biological, such as benralizumab, to help ensure the desired clinical outcome. For example, early trials of anti-IL-5 therapy for largely unselected patients with asthma failed to demonstrate clinical benefit [30-32]. In the absence of robust baseline response predictors, the success or failure of omalizumab treatment is still mainly based on re-evaluation after a therapeutic trial [33].

For patients with baseline blood eosinophil counts $<300$ cells $\mu \mathrm{L}^{-1}$, OCS use, nasal polyposis and pre-bronchodilator FVC $<65 \%$ of predicted had the greatest influence on predicting enhanced response to benralizumab Q8W for decreasing exacerbation rate, whereas history of nasal polyposis and, to a lesser extent, low baseline lung function were the most important factors for influencing benralizumab Q8W responsiveness for improving lung function. It is notable that for the subgroup of patients with blood eosinophil counts $<300$ cells $\mu \mathrm{L}^{-1}$, baseline OCS use, nasal polyps and low lung function continue to be prominent predictors of improvement in asthma exacerbations, and nasal polyps continue to predict FEV 1 response. We conclude that the presence of these features in patients with severe, exacerbation-prone asthma and blood eosinophil counts $<300$ cells $\mu \mathrm{L}^{-1}$ increases the probability that the patients' asthma is eosinophil mediated. Symptomatic improvements (either total asthma symptom score or ACQ-6) in patients with blood eosinophil counts $<300$ cells $\mu \mathrm{L}^{-1}$ were most consistently associated with current OCS use.

Several of these identified characteristics are associated with the potential pathogenic effects of eosinophilic airway inflammation. Greater airway eosinophil counts are associated with poor lung function [34], airway remodelling [35] and gas trapping [28], which reflect the characteristic of low lung function to predict enhanced benralizumab response. Elevated blood eosinophil counts are also associated with high exacerbation frequency [9], supporting the observation of exacerbation history as a predictor of response. Nasal polyposis was the most consistent predictor of benralizumab response, regardless of baseline blood eosinophil count. This is consistent with the fact that nasal polyposis is highly associated with eosinophilic inflammation of the upper airway [36], which tends to correlate with inflammation of the lower airway [37]. Hence, several of these baseline clinical features are related to the pathology of eosinophilic inflammation.

These results also indicate a potential benefit of benralizumab for patients with baseline factors that are associated with severe eosinophilic asthma, such as those evaluated in this study. For example, long-term OCS treatment is an option for patients with asthma not controlled with conventional therapies such as high-dosage ICS/LABA [4, 7]. The presence of nasal polyps for patients with adult-onset asthma is predictive of asthma severity [38]. Low FVC is associated with hyperinflation, air trapping and airflow obstruction for patients with severe asthma and with an increased risk of exacerbations [39, 40]. Thus, benralizumab treatment for patients with these baseline clinical features may modulate associated consequences of these clinical features.

One of the limitations of this study was the lower number of patients with blood eosinophil counts $<300$ cells $\mu \mathrm{L}^{-1}$ and some of the respective baseline factors evaluated. Subsequently, only trends could be identified in this subgroup; further analysis with a larger number of patients would be needed to confirm these results. For the entire pooled analyses, all comparator results of benralizumab compared with placebo used nominal p-values as they were not part of the predetermined general testing strategy. Therefore, no formal statistical significance could be inferred. Another limitation of this study was that 
certain baseline factors were self-reported (e.g. nasal polyposis) and so their prevalence may have been underestimated. Despite these limitations, the analyses reported in this article provide an evidence-based approach for targeted therapy with benralizumab.

In conclusion, this article describes several clinical characteristics also associated with the severe eosinophilic asthma phenotype [28] that complement baseline blood eosinophil counts in predicting a treatment response to benralizumab for patients with severe, uncontrolled asthma. They include OCS use, nasal polyposis, low lung function, history of frequent exacerbations and adult onset of disease. These features are easily assessed by healthcare professionals in an office setting and should help inform clinical decisions on the use of benralizumab for specific patients.

Acknowledgements: Writing and editing support, including preparation of the draft manuscript under the direction and guidance of the authors, incorporating author feedback and manuscript submission, was provided by Alan Saltzman of JK Associates (Conshohocken, PA, USA) and Michael A. Nissen of AstraZeneca (Gaithersburg, MD, USA).

Conflict of interest: E.R. Bleecker has performed clinical trials through his former employer, the Wake Forest School of Medicine, and his current employer, the University of Arizona; and has served as a paid consultant for AstraZeneca/ MedImmune, Boehringer Ingelheim, GSK, Novartis, Regeneron and Sanofi-Genzyme. M.E. Wechsler received consulting honoraria from AstraZeneca, Boehringer Ingelheim, Genentech, GSK, Novartis, Regeneron, Sanofi and Teva. J.M. FitzGerald is an advisory board member for ALK, AstraZeneca, Boehringer Ingelheim, GSK, Novartis, Sanofi-Regeneron and Teva, and has received honoraria for lectures from AstraZeneca, Boehringer Ingelheim, Cephalon/Teva, Forest, Genentech, GSK, Johnson and Johnson (Janssen), MedImmune, Novartis, Pfizer and Sanofi. A. Menzies-Gow has consultancy agreements with AstraZeneca and Vectura, was an advisory board member for AstraZeneca, Boehringer Ingelheim, GSK, Novartis and Teva, received speaker fees from AstraZeneca, Boehringer Ingelheim, Novartis, Teva, and Vectura; has participated in research that his institution has been renumerated from Boehringer Ingelheim, GSK and Hoffman La Roche, and has attended international conferences sponsored by AstraZeneca and Boehringer Ingelheim. $\mathrm{Y}$. $\mathrm{Wu}$ is an employee of AstraZeneca. I. Hirsch is an employee of AstraZeneca. M. Goldman is an employee of AstraZeneca. P. Newbold is an employee of MedImmune LLC. J.G. Zangrilli is an employee of AstraZeneca.

Support statement: Funding for this study was provided by AstraZeneca. Funding information for this article has been deposited with the Crossref Funder Registry.

\section{References}

1 To T, Stanojevic S, Moores G, et al. Global asthma prevalence in adults: findings from the cross-sectional world health survey. BMC Public Health 2012; 12: 204.

2 Wenzel S. Severe asthma: from characteristics to phenotypes to endotypes. Clin Exp Allergy 2012; 42: 650-658.

3 Wenzel SE. Asthma phenotypes: the evolution from clinical to molecular approaches. Nat Med 2012; 18: 716-725.

4 Chung KF, Wenzel SE, Brozek JL, et al. International ERS/ATS guidelines on definition, evaluation and treatment of severe asthma. Eur Respir J 2014; 43: 343-373.

5 O’Byrne PM, Pedersen S, Schatz M, et al. The poorly explored impact of uncontrolled asthma. Chest 2013; 143: 511-523.

6 Nunes C, Pereira AM, Morais-Almeida M. Asthma costs and social impact. Asthma Res Pract 2017; 3: 1.

7 Global Initiative for Asthma. Global Strategy for Asthma Management and Prevention. 2017. www.ginasthma.org/ 2017-gina-report-global-strategy-for-asthma-management-and-prevention Date last accessed: March 12, 2018.

$8 \quad$ Pavord ID. Eosinophilic phenotypes of airway disease. Ann Am Thorac Soc 2013; 10: Suppl., S143-S149.

9 Price D, Wilson AM, Chisholm A, et al. Predicting frequent asthma exacerbations using blood eosinophil count and other patient data routinely available in clinical practice. J Asthma Allergy 2016; 9: 1-12.

10 Talini D, Novelli F, Bacci E, et al. Sputum eosinophilia is a determinant of $\mathrm{FEV}_{1}$ decline in occupational asthma: results of an observational study. BMJ Open 2015; 5: e005748.

11 Bleecker ER, FitzGerald JM, Chanez P, et al. Efficacy and safety of benralizumab for patients with severe asthma uncontrolled with high-dosage inhaled corticosteroids and long-acting beta ${ }_{2}$-agonists (SIROCCO): a randomised, multicentre, placebo-controlled phase 3 trial. Lancet 2016; 388: 2115-2127.

12 FitzGerald JM, Bleecker ER, Nair P, et al. Benralizumab, an anti-interleukin-5 receptor alpha monoclonal antibody, as add-on treatment for patients with severe, uncontrolled, eosinophilic asthma (CALIMA): a randomised, double-blind, placebo-controlled phase 3 trial. Lancet 2016; 388: 2128-2141.

13 Ortega HG, Liu MC, Pavord ID, et al. Mepolizumab treatment in patients with severe eosinophilic asthma. $N$ Engl J Med 2014; 371: 1198-1207.

14 Pavord ID, Korn S, Howarth P, et al. Mepolizumab for severe eosinophilic asthma (DREAM): a multicentre, double-blind, placebo-controlled trial. Lancet 2012; 380: 651-659.

15 Castro M, Zangrilli J, Wechsler ME, et al. Reslizumab for inadequately controlled asthma with elevated blood eosinophil counts: results from two multicentre, parallel, double-blind, randomised, placebo-controlled, phase 3 trials. Lancet Respir Med 2015; 3: 355-366.

16 Fowler SJ, Tavernier G, Niven R. High blood eosinophil counts predict sputum eosinophilia in patients with severe asthma. J Allergy Clin Immunol 2015; 135: 822-824.

17 Hastie AT, Moore WC, Li H, et al. Biomarker surrogates do not accurately predict sputum eosinophil and neutrophil percentages in asthmatic subjects. J Allergy Clin Immunol 2013; 132: 72-80.

18 Wagener $\mathrm{AH}$, de Nijs SB, Lutter R, et al. External validation of blood eosinophils, $\mathrm{FE}_{\mathrm{NO}}$ and serum periostin as surrogates for sputum eosinophils in asthma. Thorax 2015; 70: 115-120.

19 Kolbeck R, Kozhich A, Koike M, et al. MEDI-563, a humanized anti-IL-5 receptor alpha mAb with enhanced antibody-dependent cell-mediated cytotoxicity function. J Allergy Clin Immunol 2010; 125: 1344-1353.

20 Pham TH, Damera G, Newbold P, et al. Reductions in eosinophil biomarkers by benralizumab in patients with asthma. Respir Med 2016; 111: 21-29. 
21 Laviolette M, Gossage DL, Gauvreau G, et al. Effects of benralizumab on airway eosinophils in asthmatic patients with sputum eosinophilia. J Allergy Clin Immunol 2013; 132: 1086-1096.

22 Sehmi R, Lim HF, Mukherjee M, et al. Benralizumab attenuates airway eosinophilia in prednisone-dependent asthma. J Allergy Clin Immunol 2018; 141: 1529-1532.

23 Nair P, Wenzel S, Rabe KF, et al. Oral glucocorticoid-sparing effect of benralizumab in severe asthma. $N$ Engl $J$ Med 2017; 376: 2448-2458.

24 AstraZeneca. Fasenra ${ }^{\mathrm{TM}}$ (Benralizumab). Prescribing Information. 2017. www.azpicentral.com/fasenra/fasenra_pi. pdf Date last updated: November, 2017. Date last accessed: January 10, 2018.

25 AstraZeneca. Fasenra ${ }^{\mathrm{TM}}$ (Benralizumab). Summary of Product Characteristics. 2018. http://ec.europa.eu/health/ documents/community-register/2018/20180108139598/anx_139598_en.pdf Date last accessed: March 13, 2018.

26 FitzGerald JM, Bleecker ER, Menzies-Gow A, et al. Predictors of enhanced response with benralizumab for patients with severe asthma: pooled analysis of the SIROCCO and CALIMA studies. Lancet Respir Med 2018; 6: 51-64.

27 Juniper EF, Svensson K, Mork AC, et al. Measurement properties and interpretation of three shortened versions of the asthma control questionnaire. Respir Med 2005; 99: 553-558.

28 de Groot JC, ten Brinke A, Bel EH. Management of the patient with eosinophilic asthma: a new era begins. ERJ Open Res 2015; 1: 00024-2015.

29 Buhl R, Humbert M, Bjermer L, et al. Severe eosinophilic asthma: a roadmap to consensus. Eur Respir J 2017; 49: 1700634

30 Leckie MJ, ten Brinke A, Khan J, et al. Effects of an interleukin-5 blocking monoclonal antibody on eosinophils, airway hyper-responsiveness, and the late asthmatic response. Lancet 2000; 356: 2144-2148.

31 Flood-Page PT, Menzies-Gow AN, Kay AB, et al. Eosinophil's role remains uncertain as anti-interleukin-5 only partially depletes numbers in asthmatic airway. Am J Respir Crit Care Med 2003; 167: 199-204.

32 Kips JC, O'Connor BJ, Langley SJ, et al. Effect of SCH55700, a humanized anti-human interleukin-5 antibody, in severe persistent asthma: a pilot study. Am J Respir Crit Care Med 2003; 167: 1655-1659.

33 Bousquet J, Rabe K, Humbert M, et al. Predicting and evaluating response to omalizumab in patients with severe allergic asthma. Respir Med 2007; 101: 1483-1492.

34 ten Brinke A, Zwinderman AH, Sterk PJ, et al. Factors associated with persistent airflow limitation in severe asthma. Am J Respir Crit Care Med 2001; 164: 744-748.

35 Inoue $\mathrm{H}$, Ito I, Niimi A, et al. CT-assessed large airway involvement and lung function decline in eosinophilic asthma: the association between induced sputum eosinophil differential counts and airway remodeling. $J$ Asthma 2016; 53: 914-921.

36 Gevaert P, Hellman C, Lundblad L, et al. Differential expression of the interleukin 5 receptor alpha isoforms in blood and tissue eosinophils of nasal polyp patients. Allergy 2009; 64: 725-732.

37 Ediger D, Sin BA, Heper A, et al. Airway inflammation in nasal polyposis: immunopathological aspects of relation to asthma. Clin Exp Allergy 2005; 35: 319-326.

38 Westerhof GA, Coumou H, de Nijs SB, et al. Clinical predictors of remission and persistence of adult-onset asthma. J Allergy Clin Immunol 2018; 141: 104-109.

39 Sorkness RL, Bleecker ER, Busse WW, et al. Lung function in adults with stable but severe asthma: air trapping and incomplete reversal of obstruction with bronchodilation. J Appl Physiol 2008; 104: 394-403.

40 Tanaka A, Uno T, Sato H, et al. Predicting future risk of exacerbations in Japanese patients with adult asthma: a prospective 1-year follow up study. Allergol Int 2017; 66: 568-573. 